\title{
Traduzir o queer: uma opção viável?
}

\author{
Anselmo Peres Alós' (iD) 0000-0003-2062-2096 \\ 'Universidade Federal de Santa Maria, Departamento de Letras Vernáculas, Programa \\ de Pós-Graduação em Letras, Santa Maria, RS, Brasil. 97105-115-ppgletras@ufsm.br
}

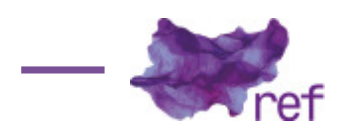

Resumo: O objetivo do presente ensaio é discutir como (se possível) deveríamos traduzir a ideia de 'queer' (tal como no sintagma 'teoria queer'), do inglês para o português. Nosso interesse não é simplesmente o de traduzir o termo 'queer', mas sim discutir o que podemos ganhar e/ou o que podemos perder no processo de tradução e adaptação da teoria queer, deslocando-a de seu contexto anglófono e realocando-a em um contexto lusófono, em especial quando se leva em consideração a articulação da teoria na análise cultural e na crítica literária fora de contextos anglófonos.

Palavras-chave: Teoria queer; tradutologia; gênero; sexualidade.

Translating the Queer: A Feasible Option?

Abstract: The aim of this essay is to discuss how (if possible) we should translate the idea of 'queer' (as in 'queer theory' from English to Portuguese. Our interest is not simply to translate the word 'queer', but to discuss what could be gained or loss in the process of translation and adaptation of queer theory from Anglophone to Lusophone contexts, in terms of the articulation of the theory in cultural analysis and literary criticism outside the Anglophone contexts.

Keywords: Queer theory; Trans/ation Studies; Gender; Sexuality.

\section{Primeiras palavras: breves apontamentos sobre tradução}

Começo essa intervenção com algumas perguntas um tanto impertinentes: como se traduz ao português a palavra dépaysement (do francês, o sentimento que aflige quem está fora de seu país natal e dele sente falta)? Como se traduz strogonoff (o famoso prato russo que se aclimatou tanto ao gosto brasileiro)? Ou, colocando o português no lugar de língua de partida, e não o de língua de chegada, como traduzir saudade?

Como se traduz akimbo? Em inglês, akimbo designa a posição de "mãos na cintura, com os cotovelos apontando para fora"; saudade pode ser traduzido ao inglês como "to miss somebody, or something, or some place". Não há uma correspondência termo a termo entre português e inglês, assim como frequentemente não há entre uma língua e outra; de mesmo modo, não há correspondência absoluta entre todos os elementos de uma cultura e de outra. Muitas vezes, é necessária uma longa perífrase, ou uma abastada nota de rodapé, para traduzir certas palavras ou expressões de uma língua a outra. Quem já se aventurou a traduzir um trecho qualquer de uma língua estrangeira para a sua língua primeira, mesmo um simples parágrafo de outrem para utilização em um artigo in progress, como citação, sabe bem que muitas vezes as notas de rodapé são a única possibilidade de se fazer a transposição de uma língua a outra (isto é, 'de uma cultura a outra') com 'um pouco mais de eficiência'. A questão que importa aqui é: o que ganhamos e o que perdemos com uma transposição cultural?

É da própria natureza da linguagem não apreender o real completamente: lembremos da distinção lacaniana (Cf. Jacques LACAN 1960; 1973-1974; 1974-1975; 1978; 1985; 2003; 2007) entre o 'Real' (aquilo que é inapreensível pela linguagem) e a 'realidade' (que é da ordem do simbólico, ou seja, o 'Real' ao qual se pode atribuir sentido através da mediação pela linguagem). Em outras palavras, se não há correspondência termo a termo (i. e., 'absoluta') entre 'linguagem' e 
'mundo', tampouco há correspondência 'absoluta' entre uma língua e outra. Retomo aqui um exemplo já quase lugar-comum: o dos itens lexicais utilizados em distintas línguas para "recortar" o espectro luminoso. Em coreano e em algumas línguas bantu, há uma única palavra para descrever a faixa espectral que vai do verde ao azul. Em sérvio, há quatro palavras para descrever o que chamamos (em português) de azul. Em mandarim, rosa é apenas uma tonalidade de vermelho, enquanto em português 'vermelho' e 'rosa' são cores-palavras absolutamente distintas (Cf. Brent BERLIN; Paul KAY, 1969), entidades linguístico-culturais que apontam para campos semânticos distintos e quase óbvios para um falante nativo de português (o campo da 'feminilidade', no caso de 'rosa'; o campo 'bélico-conflitivo', no caso do 'vermelho').

Um segundo ponto a ser levantado é: o que entendemos por 'tradução'? Apenas para tomar duas das concepções mais extremistas, se levamos em conta a hipótese Sapir-Woolf (Cf. Paul KAY; Willett KEMPTON, 1984), a tradução sempre seria distorção e traição, pois cada língua carregaria em seu sistema uma concepção única de mundo (logo, toda tradução implica 'perda de sentido' quando confrontada com o original); se nos alinhamos com as discussões e propostas de Haroldo e Augusto de Campos (1968), bem como Haroldo de Campos (2006), na esteira do "Manifesto Antropófago" de Oswald de Andrade (1976) (publicado pela primeira vez em maio de 1928), toda tradução é canibalização, deglutição e digestão; toda tradução é tradução criativa, é 'transcriação'. Não vou me estender nas diferentes perspectivas do trabalho tradutório, pois esse não é o ponto em relevo aqui. Como consequência, toda tradução implicaria um 'ganho', um 'excesso' e um 'transbordamento' quando confrontada com o original (na perspectiva dos irmãos Campos). Se formos um pouco mais além e adentrarmos os meandros da filosofia derrideana, todo enunciado traduzido funciona dentro de uma lógica suplementar ao seu respectivo "original" (Cf. Jacques DERRIDA, 1973). Longe de adotar qualquer uma dessas posições mais extremadas, o que me interessa deixar no ar como questão norteadora aqui é o seguinte: traduzir o queer implica (ao menos potencialmente) uma 'perda', ou um 'ganho', ou 'ambos' ao mesmo tempo? Logo, devemos manter-nos vigilantes com o que ganhamos e/ou com o que perdemos quando o "traduzimos".

\section{Tradução, 'tradutibilidade' e a migração de conceitos teóricos}

Saindo do campo das palavras "intraduzíveis", gostaria de retomar uma série de expressões que são absolutamente traduzíveis, mas que não traduzimos, ou por conveniência, ou porque elas já se tornaram tão transparentes no uso cotidiano em português que dispensariam tradução: shopping center ("centro de compras"); mouse ("rato", como se usa no português europeu); hardware ("máquina"), em oposição a software ("programa"); wireless ("sem fio"). Cabe lembrar ainda que falamos, em nosso linguajar corriqueiro, abajour (e não luminária); 'futebol' (e não ludopédio). Não pretendo explorar juízos de valor com relação a esses usos, mas tão somente fazer algumas constatações: primeiro, que empréstimos sempre estiveram presentes na história das línguas; segundo, que alguns empréstimos incomodam mais do que outros (Cf. Steven CONNOR, 1992); terceiro, e último: se é verdade que há um incômodo e uma espécie de "pulsão de tradução" quando se discute o queer (seja meramente o termo, seja a "teoria queer"), o mesmo dificilmente acontece com o termo gay. Isso mereceria uma discussão também: por que insistimos na discussão de uma questão tal qual "traduzir o queer", enquanto "traduzir o gay" nunca foi, ao menos até onde sei, objeto de discussão mais acalorada na academia brasileira? Alternativas como usar 'viado' ou 'guei' chegaram a ser articuladas em alguns periódicos, com finalidades políticas decoloniais avant la lettre, mas o vocábulo gay não parece ter 'incomodado' tanto quanto o queer. Veja-se, nesse sentido, as colunas e artigos do Lampião da Esquina, ${ }^{1}$ os artigos de João Silvério Trevisan (2000), ou alguns usos mais recentes que podem ser vislumbrados nas páginas virtuais de Periódicus. ${ }^{2}$

Antes de traduzir (ou de 'não traduzir') o queer, parece-me pertinente retomar um pouco do contexto do termo. Em inglês, queer possui uma carga semântica muito 'pesada', 'espessa' e 'opaca'. Na linguagem ordinária, queer (o adjetivo) carrega os sentidos de 'bizarro', 'estranho', 'anormal', freak, 'não natural', 'não convencional'. Especula-se que o vocábulo tenha surgido no Baixo Alemão, quer (significando 'oblíquo', 'perverso'), e teria migrado para o inglês por volta do século XVI. Como adjetivo, queer não era uma palavra cujo sentido estaria associado às sexualidades dissidentes. É apenas com a utilização na forma nominal, the queer, que o termo passa a ser utilizado como substantivo para designar, pejorativamente, os homossexuais - em um primeiro momento, homens homossexuais e, ao longo dos séculos XIX e XX, todo e qualquer sujeito de sexualidade 'indesejável' (Cf. Anselmo Peres ALÓS, 2011; 2013; Guacira Lopes LOURO, 2004; Annamarie JAGOSE, 1996).

\footnotetext{
1 Jornal escrito por intelectuais homossexuais e dirigido ao público homossexual brasileiro que circulou entre 1978 e 1981.

2 Periódicus é uma publicação semestral de divulgação científica do Grupo de Pesquisa CUS - Cultura e Sexualidade, criado em 2007 e vinculado à Universidade Federal da Bahia. Até outubro de 2018 , o periódico havia publicado nove números. Disponível em https://portalseer.ufba.br/index.php/revistaperiodicus. Acesso em 13/10/2018.
} 
Em especial ao longo do século XX, a expressão hey you, queer! torna-se um insulto particularmente ultrajante. Mobilizado pelos discursos de ódio de caráter homofóbico direcionados a gays, lésbicas, travestis e transexuais, o termo teria o peso que os termos 'puta', 'bicha', 'viado' e 'sapatão' (ou os termos rosquete, maricón e marimacha, em espanhol) teriam quando mobilizados de maneira a 'ofender'. É uma expressão que simultaneamente 'insulta' e 'devassa' uma identidade sexual supostamente indesejável, ao mesmo tempo em que 'rebaixa' o interlocutor a uma posição de 'abjeto', de 'menos-que-humano', ou mesmo de 'não humano'. Sobre as relações entre subjetividade homossexual e abjeção, cabe mencionar duas obras fundamentais de Judith Butler (1990; 1993): Gender Trouble e Bodies that Matter, que serão retomadas um pouco mais adiante nessa discussão.

\section{Queer: o Insulto e sua reaproprlação política}

O termo queer (nesse campo semântico do insulto, da ofensa, e da palavra-tabu) passa a ser objeto de uma reapropriação retórica e política por parte daqueles sujeitos que são por ele designados. Se é verdade que o insulto reduz a objeto a pessoa a quem se dirige, esse insulto, por sua vez, dá a possibilidade de que a pessoa insultada possa reagir, apropriar-se do insulto, e o 'ressignificá-lo politicamente' como estratégia de resistência e de subversão. Se o acusador dedo heterossexual, burguês e branco aponta para mim enquanto grita "viado, bicha louca!", isso cria a oportunidade discursiva para que eu recuse a posição de objeto e me constitua como um sujeito que: a) se reconhece 'interpelado' pelo insulto; b) que se recusa a ser objeto e assume a sua condição de sujeito histórico; c) e permite-se revidar: "não sou viado, sou viadééééééééééésima, meu cu é laico e o sexo anal derrubará o capital". ${ }^{3}$ Se eu responder "sou um homem homossexual e exijo ser respeitado", também estaremos diante de uma resposta de teor político e de um sujeito que se recusa a ser objetificado. Mas essa resposta não tem absolutamente nada de queer. A noção de interpelação ideológica na constituição da subjetividade, a partir de um mecanismo de caráter inconsciente, foi abordada por Louis Althusser (1974; 1978), e estendida por Butler (1997) em The Psychic Life of Power.

Saindo do exemplo e indo para o campo de uma provisória definição: o estratagema utilizado pelos "teóricos queer" na academia estadunidense, nesse sentido, é o de se 'reapropriar' de uma categoria cujo uso corrente é da ordem do ofensivo e do pejorativo em um gesto de autodesignação; esse gesto, ao mesmo tempo em que "desarma" o discurso homofóbico e heteronormativo, reabilita o uso do termo em um contexto não ofensivo. Para Jagose (1996), que escreveu uma espécie de "introdução" à teoria queer:

Enquanto a mobilização do termo queer em seu sentido mais recente não pode ser datada exatamente, geralmente defende-se que seu uso tem sido popularmente adotado no início dos anos 1990. Queer [no sentido que o adjetivo invoca na expressão 'teoria queer'] é o produto de pressões e negociações culturais e sociais (tanto dentro quanto fora das universidades) que enriqueceram o debate em torno das questões sobre identidade gay e lésbica. Talvez o mais significante na perspectiva queer seja a problematização, de índole pós-estruturalista, da compreensão da 'identidade' promovida pela liberação gay e pelo feminismo lésbico, que passa a ser entendida em termos de relações e operações de poder. [...] A deslegitimação de noções de identidade liberais, liberalistas, étnicas e não raro separatistas produziu as condições de emersão do termo 'queer' no contexto teórico e político; a não especificidade do queer resguarda-o das críticas feitas às tendências exclusionistas expressas pelas identidades 'gay' e 'lésbica' (p. 76 [tradução e incisa, entre colchetes, minhas]).

A citação acima remete a uma questão que me parece fundamental: a de que não é possível 'traduzir' o queer sem grandes perdas de potencial teórico e político, 'a menos que' recuperemos seu contexto de aparição e sua história, em especial no contexto estadunidense.

\section{Queer, um conceito em trânsito}

Via de regra, como já afirmou Jagose (1996), o início do que hoje denominamos de teoria queer remonta ao início da década de 1990. Todavia, o que muitas vezes se perde de vista é que o surgimento do queer não se dá exclusivamente no contexto acadêmico, mas também, e principalmente, no ativismo e nos coletivos de gays, lésbicas, travestis, transexuais e transgêneros. Se é verdade que a teoria queer fala a linguagem das universidades, também é verdade que ela fala 'a linguagem das ruas'. Frequentemente são mencionados como textos fundadores da teoria queer um livro de autoria individual, um número de periódico e um livro coletivo de ensaios, mas se esquece de um feroz, raivoso e pertinente manifesto, que me parece fundamental no delineamento das origens da teoria queer. Cabe remontar, portanto, a esses quatro 'documentos'.

\footnotetext{
${ }^{3}$ Articulo aqui, para compor a minha hipotética resposta, três enunciados políticos frequentemente vislumbrados nas faixas, cartazes e palavras de ordem das manifestações gays, lésbicas e queer em defesa da livre expressão sexual: "não sou viado, sou viadééééééééééésima", "meu cu é laico" e "sexo anal derrubará o capital".
} 
Eles não são os únicos, talvez não sejam sequer os mais importantes (arrisco a dizer que poucos "teóricos queer" enquadrariam os quatro documentos simultaneamente como "o" conjunto de textos fundadores), mas sinalizam uma origem heterogênea (ao menos, 'dupla') para a mobilização do pensamento queer: o ativismo das ruas e o pensamento acadêmico. Cumpre que se retome, ainda que brevemente, esses quatro textos.

O primeiro, seguramente o mais conhecido e o mais referenciado - e 'reverenciado' (no Brasil), é o livro de Butler (1990; 2003) intitulado Gender trouble: feminism and the subversion of identity, publicado pela primeira vez em 1990, e traduzido no Brasil apenas em 2003, sob o título Problemas de gênero. Esse livro é conhecido e reiteradamente citado (em especial no Brasil) como o texto fundador da teoria queer. Butler não é apenas a autora considerada "fundadora" da teoria queer (ao menos entre os pesquisadores brasileiros), mas também uma das filósofas mais importantes e influentes da virada do século XX para o século XXI. Todavia, Gender Trouble não é "o primeiro" texto da teoria queer. ${ }^{4}$ Não é possível localizar um texto fundador, até porque as quatro publicações às quais remonto e que discutirei brevemente aqui são de funcionamento distinto, e embora duas datem de 1990 e duas de 1991, não é possível deixar de levar em consideração que as temporalidades envolvidas na redação de 'um livro individual', de 'um manifesto coletivo', da 'organização de um número especial de uma revista acadêmica' e da 'organização e publicação de um livro coletivo', ademais de distintas, são de duração consideravelmente 'variável', envolvendo distintas dinâmicas, distintos interesses, distintos autores e distintas estratégias políticas e textuais.

Também em 1990, emerge no cenário estadunidense um texto quase desconhecido e quase nada acadêmico: "A Queer Manifesto" (1990), anônimo e coletivo, foi um texto gratuitamente distribuído nas ruas ao longo da Gay Pride de 1990, em New York. Trata-se de um panfleto-manifesto, de fundo político radical, e não de um ensaio acadêmico. Recentemente foi traduzido e publicado (em 2016), em Belo Horizonte, e pode ser facilmente encontrado (tanto o original quanto a versão em português) com uma busca na internet (MANIFESTO QUEER NATION, 2016). Gostaria de citar um breve trecho (o texto possui cerca de dez páginas), para trazer à tona o "tom" desse manifesto. Seu traço mais marcante é que ele "rompe" com o establishment gay e lésbico estadunidense, que poderia ser representado, por exemplo, com a visibilidade de gays "higienizados" em programas televisivos como Will and Grace, ou de comportadas lésbicas que não saíam do armário, tais como Ellen (interpretada por Ellen Degeneris), do sitcom de mesmo nome:

Odeio heterossexuais que pensam ter algo inteligente a dizer sobre 'sair do armário'. Odeio heterossexuais que pensam que suas histórias são 'universais', enquanto as nossas interessam apenas a homossexuais. Odeio músicos heterossexuais que fazem suas carreiras decolarem às custas do povo queer e depois nos atacam, sentindo-se feridos quando demonstramos raiva e negando terem nos traído ao invés de se desculparem. Eu odeio o fato de que em vinte anos de educação pública jamais fui ensinada sobre o povo queer (MANIFESTO QUEER NATION, 2016, p. 7).

O terceiro documento que eu gostaria de trazer à baila nem é tão desconhecido quanto 0 Queer Nation Manifesto, tampouco tão popular quanto o livro de Judith Butler. Trata-se de um número especial do periódico acadêmico feminista Differences: A Journal of Feminist Cultural Studies. Em sua edição de verão de 1991 (volume 3, número 2), sob a coordenação de Teresa De Lauretis (1991), é publicado um volume especial, sob o título "Queer theory: lesbian and gay identities". Italiana de nascimento, professora de semiótica e teoria do cinema, lésbica e feminista, com um doutorado orientado por Umberto Eco, De Lauretis atua como professora e pesquisadora nos Estados Unidos, no Departamento de História da Consciência da Universidade de Santa Cruz, na Califórnia. O número especial que ela organiza traz um importante número de pesquisadores das mais diversas áreas (psicanálise, literatura, cinema e antropologia) que problematizam e discutem problemas teóricos e metodológicos envolvendo questões de identidade gay e lésbica a partir de um prisma pós-estruturalista. Finalmente, também em 1991, é publicada a coletânea de ensaios Inside/out: lesbian theories, gay theories [Assumidxs|enrustidxs: teorias lésbicas, teorias gays], editada por Diana Fuss (1991). Os inúmeros trabalhos incluídos nesse livro coletivo ocupamse em discutir a questão das identidades gay e lésbica a partir de lentes interdisciplinares, que articulam em sua metodologia de trabalho campos diversos tais como a psicanálise, o feminismo, a sociologia e a semiótica, a partir de uma perspectiva de índole pós-estruturalista. Da mesma forma que a edição da Differences organizada por De Lauretis, esse volume é bem pouco discutido e citado entre os pesquisadores brasileiros que se identificam com perspectivas de investigação que se alinham a um enquadramento queer.

Uma poeta e pensadora extremamente relevante para a discussão dos primeiros momentos não apenas da teoria queer, mas para o feminismo da diferença, articulando em seus escritos postulados interseccionais e queer avant la lettre, em perspectiva transnacional, é Gloria Anzaldúa

\footnotetext{
${ }^{4}$ A própria Judith Butler, ao longo da década de 1990, não se identificou de imediato como uma "teórica queer". Ela apresentava-se como uma 'filósofa', como uma 'feminista', como uma 'lésbica', e como uma 'judia secular'. É justamente a 'rasura' da identidade única, coesa e de índole essencializante que, em certo sentido, caracterizaria uma 'postura' ou um 'gesto analítico-interpretativo' de natureza queer.
} 
(1987). Entre seus principais trabalhos, o livro autobiográfico (por vezes também descrito como auto-história ou 'autoteoria') Borderlands/La Frontera: The New Mestiza, é uma obra que mistura prosa, poesia e pensamento teórico, na qual conta sua trajetória como acadêmica e mulher chicana. Anzaldúa articula em sua dicção sua lesbianidade, seu feminismo, sua condição de trabalhadora e de migrante de um modo interseccional e transnacional, o que é de fundamental importância para explicitar que o pensamento queer, desde suas origens, está atento e aberto ao diálogo para a discussão de questões de raça, classe, etnia, nacionalidade, decolonialidade e migração, ademais das óbvias preocupações com o gênero e a sexualidade. Transcrevo abaixo, no original, um pequeno trecho do livro, no qual o termo queer é articulado em uma discussão teórica, no sentido de reapropriação do termo, que o 'ressemantiza' substituindo o que havia de ofensivo no termo, reenquadrando-o em um contexto de subversão e resistência epistêmica:

As a mestiza I have no country, my homeland cast me out; yet all countries are mine because I am every womanls sister or potential lover. (As a lesbian I have no race, my own people disclaim me; but I am all races because there is the queer of me in all races). I am culture less because, as a feminist, I challenge the collective cultural/religious male-derived beliefs of Indo-Hispanics and Anglos; yet I am cultured because I am participating in the creation of yet another culture, a new story to explain the world and our participation in it, a new value system with images and symbols that connect us to each other and to the planet. Soy un amasamiento, I am an act of kneading, of uniting and joining that not only has produced both a creature of darkness and a creature of light, but also a creature that questions the definitions of light and dark and gives them new meanings ${ }^{5}$ (ANZALDÚA, 1987, p. 80-81 [itálicos do original, negritos meus]).

À exceção do "Manifesto Queer Nation" e do número especial da revista Differences, os outros dois textos não fazem menção ao queer (não explicitamente, ao menos, em seus respectivos títulos) como vertente teórica. O termo surge com o peso de vertente teórica a posteriori, por volta da metade dos anos 1990, justamente para diferenciar o espectro político antiassimilacionista dessas discussões quando confrontado com os chamados "estudos gays e lésbicos", relativamente consolidados em alguns centros de ensino e pesquisa estadunidenses desde o final da década de 1980. Veja-se, a título de ilustração, as discussões de Douglas Crimp (1988), bem como Crimp e Adam Rolston (1990). Com fins didáticos, acho que pode ser interessante estabelecer uma espécie de "quadro comparativo", de modo a distinguir as linhas de força preponderantes nos gay and lesbian studies e nos queer studies.

Antecedentes feministas: os estudos gays e lésbicos não necessariamente dialogam ou pressupõem (e, com certa frequência, ignoram ou desconhecem) os avanços teóricos e epistemológicos conquistados pelo feminismo acadêmico quando tentam desenvolver seus modelos teórico-críticos. Não raro, os estudos gays e lésbicos são "muito gays e pouco ou nada lésbicos", frequentemente esquecendo o quanto compactuaram (ou o quanto 'ainda' compactuam) com o masculinismo, com a hegemonia euro-estadunidense e com os privilégios raciais da 'branquitude', entendida como grau zero da identidade étnico-racial. O pensamento queer por definição pressupõe o feminismo (tanto teórico quanto histórico - pois seus nomes "fundadores" são de lésbicas feministas atuando na academia) e vai além de uma política identitária afirmativa. O queer é interseccional avant la lettre. Onde a 'teoria gay' diz 'identidade', a 'teoria queer' diz 'fluidez antiessencialista'. Quando a 'teoria gay' diz 'representatividade', a 'teoria queer' diz 'subversão'.

A categoria 'identidade': os estudos gays e lésbicos são frequentemente identitários, daí sua aposta em imagens positivas de gays e lésbicas na mídia, sua insistência em políticas identitárias e de representação, e sua problemática relação com "a margem da margem" (gays afeminados, lésbicas masculinizadas, sujeitos transexuais ou transgêneros) e com as subjetividades "exóticas" (afrodescendentes, latinas, nipônicas, imigrantes, orientais etc.), independentemente da identidade de gênero reivindicada. A homossexualidade nem sempre é tratada em conjunto com a problematização dos binarismos de gênero. Não raro recai-se em universalismos essencializantes que - me parece - podem ser bastante problemáticos (por vezes os "estudos gays" reiteram um modelo branco, masculinista e viril de homossexualidade, quase tão excludente quando o modelo branco, burguês e heterossexual de masculinidade, como já foi apontado no trabalho de Robert William Connell (1995), em especial no que diz respeito à noção de

\footnotetext{
5 "Como mestiza, eu não tenho país, minha terra natal me despejou; no entanto, todos os países são meus porque eu sou a irmã ou a amante em potencial de todas as mulheres. (Como uma lésbica não tenho raça, meu próprio povo me rejeita; mas sou de todas as raças porque a queer em mim existe em todas as raças.) Sou sem cultura porque, como uma feminista, desafio as crenças culturais/religiosas coletivas de origem masculina dos indo-hispânicos e anglos; entretanto, tenho cultura porque estou participando da criação de uma outra cultura, uma nova história para explicar o mundo e a nossa participação nele, um novo sistema de valores com imagens e símbolos que nos conectam um/a ao/à outro/a e ao planeta. Soy un amasamiento, sou um ato de juntar e unir que não apenas produz uma criatura tanto da luz como da escuridão, mas também uma criatura que questiona as definições de luz e de escuro e dá-lhes novos significados" (ANZALDÚA, Gloria. "La conciencia de la mestiza / Rumo a uma nova consciência". Tradução de Ana Cecília Acioli Lima. Revisão da Tradução por Susana Bornéo Funck. Revista Estudos Feministas, Florianópolis, v. 13, n. 3, p. 704-719, 2005. Disponível em http://www.scielo.br/pdf/ref/v13n3/a15v13n3.pdf. Acesso em 19/10/2019).
} 
"masculinidades subalternizadas". Já os estudos queer, por sua vez, são pós-identitários, antiessencialistas, e consideram a 'identidade' como precária, histórica, contingente e performativa. Os estudos queer rejeitam as perspectivas universalistas e celebram o local e o 'glocal' (tudo está localizado em temporalidades e espacialidades, na história e na geografia, em especial quando estamos lidando com 'corpos', 'desejos', 'prazeres' e 'afetos').

Integração e assimilação: os estudos gays e lésbicos buscam a integração na sociedade civil de matriz heterossexual pautada pelo Estado e pela Nação. Em sua agenda política, está a luta pelos direitos ao casamento, à adoção, ao ingresso nas forças armadas, ao reconhecimento do status de família a partir de arranjos familiares calcados em modelos heterossexuais (monogamia, casais 'estáveis e exclusivos', direitos de propriedade e de transmissão de herança). Já os estudos queer, por sua vez, são subversivos e antiassimilacionistas por definição. Não querem direito ao casamento, pois questionam a monogamia e o casamento como contratos heteronormativos; não querem o direito de ingresso nas forças armadas, pois são antimilitaristas; ${ }^{6}$ questionam a família nuclear como modo de organização social, ${ }^{7}$ e pensam em outros arranjos ('poliamor', comunidades, confrarias e 'fraternidades') e não desejam ser reconhecidos pelo Estado, ${ }^{8}$ pois sabem que ser reconhecido pelo Estado faz parte dos interesses 'biopolíticos' do Estado (Cf. Sarah SCHULMAN, 2009). A 'biopolítica', para Michel Foucault (1988; 1990), é uma das modalidades de poder que o Estado articula para administrar, dominar e controlar as populações humanas de acordo com seus próprios interesses.

Estado e Nação: os estudos gays e lésbicos não raro são nacionalistas, e projetam as especificidades do North American gay way of life como modelo universal de homossexualidade; em sua agenda política, buscam a integração e o reconhecimento dos sujeitos gays e lésbicas na 'nação' e o seu reconhecimento frente ao Estado (Jasbir PUAR, 2007; SCHULMAN, 2012). Frequentemente as lésbicas são vistas apenas como 'mulheres gays' (ignorando-se completamente as premissas que hoje chamamos de 'interseccionais'). Já o pensamento queer é transnacional e não integracionista. Ao invés de desejar o desejo do Estado, questiona o poder que o Estado tem nas vidas pública e privada dos sujeitos e das populações (Cf. BUTLER, 2004; Richard MISKOLCI, 2013).

Gênero como categoria analítica: os estudos gays e lésbicos por vezes "derrapam". Eles não apenas aceitam - com certa frequência e acriticamente - o modelo binário de gênero homem/masculino e mulher/feminino, como por vezes reiteram esse modelo (travestis, transexuais e transgêneros, lésbicas masculinizadas e gays efeminados não raro orbitam nas margens do mundo gay e lésbico, mas também são "indesejados"). Já o pensamento queer toma como pedra de toque o questionamento do sistema binário de gênero, que é visto como um 'dispositivo' fundamental de manutenção da heteronormatividade e da heterossexualidade compulsória (BUTLER, 1990; 2004; DE LAURETIS, 1991; FUSS, 1991). O pensamento queer realiza também uma crítica à objetividade científica, uma vez que os discursos da medicina, da psiquiatria, da biologia e da psicologia, 'científicos' por definição, foram responsáveis por muito tempo pela segregação étnica, racial, de gênero e de orientação sexual. Basta que se lembre aqui das teorias "científicas" utilizadas para justificar o racismo e para patologizar qualquer expressão sexual fora do interesse do Estado. Ver, nesse sentido, as discussões de Foucault (1997; 1989) acerca da 'disciplina' e do 'saber/poder'.

Dentro de uma perspectiva queer, a identidade não é uma totalidade, uma mônada, uma essência, ou mesmo o 'resultado acabado' de um processo. A identidade, tal como o próprio 'sujeito', é concebida como performatividade, isto é, como resultado de processos discursivos iteráveis e reiteráveis ao logo do tempo. Butler já alertava que essa concepção de sujeito, que não o vê mais como 'origem do discurso', mas sim como 'um efeito de discursos', não implica nem a morte da política, tampouco a impossibilidade de intervenção no contexto social (BUTLER, 1990; 1993). Implica, entretanto, uma urgente reavaliação de nosso entendimento do que seja 'ação política' e do que seja 'intervenção', fazendo-nos ir um pouco mais além, de modo a adentrar os domínios da ética. O sujeito deve ser lido como a marca e um interesse socialmente construídos e inseridos no corpo. Tal como alerta Patrick McGee (1992), "I have to make decisions that are ethically responsible based on my 'lived' relation to the world of interests. It would be irresponsible, however, to imagine that such a lived relation is the final limit of my responsibility" [eu tenho de tomar decisores eticamente responsáveis baseando-me na minha relação 'vivida' com o mundo dos interesses. Seria irresponsável, entretanto, imaginar que tal relação vivida seja o limite final da minha responsabilidade] (p. 39 [tradução minha]).

\footnotetext{
"Cf. Jasbir Puar (2007) e a sua discussão em torno da questão do "homonacionalismo" militarista, em especial no caso de Israel.

${ }^{7}$ Cf. Schulman (2009), e a noção de 'homofobia familiar' por ela desenvolvida.

${ }^{8}$ Com respeito ao papel regulador do Estado e da heteronormatividade da família nuclear e da concepção de "parentesco" (Cf. BUTLER, 2004).
} 


\section{Considerações finais: queer à brasileira}

Em 2001, Mário César Lugarinho já havia tentado responder à pergunta que implicitamente está contida no título deste ensaio. No momento em que escrevo essas linhas, dezessete anos separam-me do momento em que Lugarinho (2001) publicou seu "Como traduzir a teoria queer para a língua portuguesa". Quase duas décadas separam nossas tentativas de responder à questão, mas ela ainda não está de todo esgotada. Quero voltar à questão inicial aqui: como traduzir o queer? Pergunto-me isso há quase duas décadas e, por ora, a minha resposta é: 'talvez o melhor seja não traduzir'. Melhor dizendo, minha opção pessoal, como pesquisador, é por não traduzir o termo. Prefiro não correr o risco de perder a voltagem política e a história carregada pela espessura semântica do queer em uma tradução que o domestique, que o pasteurize, que o edulcore. Essa é uma opção pessoal. Mas não preciso relembrar aqui que 'o pessoal é político'. As feministas que vieram antes de nós, que nos queremos queer, já nos ensinaram isso.

Felizmente, parte da discussão brasileira começa a despertar para tais questões. Larissa Pelúcio (2014), em "Traduções e torções, ou o que se quer dizer quando dizemos queer no Brasil?", propõe um deslocamento interessante para o termo, buscando na poesia do poeta e antropólogo Nestor Perlongher a possibilidade de uma 'teoria cu', jogando com o tabu, com o desejo, com a interdição e com a abjeção relacionadas ao cu amplamente identificáveis na cultura brasileira, e muito provavelmente extensíveis ao mundo hispano-americano. Em outro artigo, intitulado "Subalterno quem, cara pálida? Apontamentos às margens sobre pós-colonialismos, feminismos e estudos queer", Pelúcio (2012) tece considerações importantes acerca de uma retomada do queer em um contexto marcado por uma visada feminista e pós-colonial, invocando questões étnico-raciais para o debate. Não acredito que manter o uso do termo queer em português seja uma postura de subserviência ao imperialismo anglófono. A maior parte da teoria literária estruturalista, ao longo da segunda metade do século XX, embora bem e bastante traduzida do francês para o português, não nos livrou de um certo colonialismo intelectual à francesa, vendo em Gérard Genette (2009) o ápice da narratologia, ${ }^{9}$ ou insistindo na caduca defesa das "altas literaturas", do cânone literário, da literatura "de verdade" e da inviolabilidade da 'literariedade' como ponto de chegada e de partida do nosso trabalho como críticos, pesquisadores e docentes, no caso específico do campo dos estudos literários. Não podemos perder de vista que, no atual cenário planetário, para o bem e para o mal, o inglês é 'língua franca'. Importantes movimentos em defesa dos direitos humanos no Oriente Médio, como o Ira Queer, ${ }^{10}$ no Iraque, ou o Al Qwals, ${ }^{11}$ na Palestina, que mobilizam o queer como aposta política transnacional em um contexto linguístico onde o árabe cumpre um importante papel de resistência linguística anti-imperialista.

Na cena pública brasileira, é frequente o recurso a siglas aglutinantes, que esboçam uma política de coalizão que se pretende aparentada ao queer, tais como GLS ('gays', 'lésbicas' e 'simpatizantes'), LGBT ('lésbicas', 'gays', 'bissexuais' e 'travestis'), ou ainda LGBTTII ('lésbicas', 'gays', 'bissexuais', 'travestis', 'transexuais', 'transgêneros' e 'intersexuais'). Essas siglas não traduzem a complexidade das abordagens queer, pois pressupõem e insistem nas políticas identitárias expressas por cada uma das letras nas siglas. Incluir um ' $Q$ ' nas siglas (de forma a marcar a presença do queer nessa "sopa de letrinhas"12) tampouco é uma alternativa, pois o ponto de partida do queer é o questionamento da identidade estável. O queer não pode ser subsumido em uma política identitária, por mais ampla que ela se pretenda.

O queer não é, nem se pretende, uma identidade. Como lugar de articulação teórica, como espaço epistêmico de produção de conhecimentos politicamente situados, o queer é um lugar de crítica, um ponto de vista, um locus epistemológico para se pensar questões de corpo, sexo, gênero e sexualidade. Dizer "eu sou queer" diz tanto sobre a minha sexualidade quanto dizer "eu sou estruturalista" ou "eu sou marxista". O queer não é uma identidade sexual, não descreve (tampouco prospecta) uma identidade calcada em algum desejo desviante. O queer é um gesto analítico, é uma postura epistêmica, é um espaço de articulação e de produção de conhecimento ou, ainda, uma possibilidade de 'enquadramento'; ele não é um mero locus de enunciação, ou um 'lugar de fala', para remontar à categoria tão popularizada recentemente na academia e nos movimentos sociais brasileiros em função do trabalho de Djamila Ribeiro (2016).

Todavia, dizer que não se traduz o queer não implica dizer que não seja possível uma prática ou uma operacionalização da teoria queer à brasileira. Podemos pensar em alguns exemplos, tais como o resgate do termo 'viado' ou o uso do termo 'guei' ('as guei', no feminino), como feito pelo Lampião da Esquina (1978-1981), ou pelo Jornal do Nuances (1998-2007). Esse gesto de autodenominação política pode ser lido como atitude análoga aos procedimentos epistemológicos do pensamento queer. Todavia, tal como podemos perceber pela própria

\footnotetext{
${ }^{9}$ Ver, a esse respeito, a recente tradução de Genette (2009).

${ }^{10}$ Cf. Website do Ira Queer. Disponível em https://www.iraqueer.org/. Acesso em 20/10/2018.

${ }^{11}$ Cf. Website do Al Qwals. Disponível em http://alqaws.org. Acesso em 20/10/2018.

${ }^{12}$ Faço aqui uma menção indireta ao livro de Regina Facchini (2005), intitulado Sopa de letrinhas? Movimento homossexual e produção de identidades coletivas nos anos 90 .
} 
materialização textual dos jornais citados a título de exemplo, corre-se o risco de excluir as mulheres - e, particularmente, as mulheres lésbicas e transexuais - da discussão.

No outro extremo do continuum de gênero, o 'putafeminismo' do ensaio-manifesto assinado pela puta e ativista Monique Prada (2018), ou a grife Daspu, ${ }^{13}$ idealizada por Gabriela Leite (que vendia 'para putas' roupas concebidas, desenhadas e costuradas 'por putas'), podem também ser lidos como gestos de resistência queer antiassimilacionistas. Utilizo aqui a "categoria nativa" 'puta', tal como se costuma dizer em antropologia cultural, uma vez que esse é o termo em torno (e a partir do qual) mulheres como Gabriela Leite e Monique Prada constituem suas identidades como trabalhadoras sexuais. Uma boa extensão do livro de Prada (2018) discute justamente sua opção por resgatar o termo 'puta' e recusar os termos 'prostituta' ou 'trabalhadora sexual'. Aqui, o risco é deixar os homens de fora, uma vez que, até onde eu saiba, não houve, em nenhum momento da história brasileira, ou mesmo ocidental, algum movimento de associativismo e/ou coalizão entre putas e michês. Arrisco inclusive a dizer que em nenhum momento houve alguma tentativa de colaboração associativa entre michês e putas: se as putas têm um senso de identidade coletiva, o mesmo não pode ser dito dos michês (Cf. Nestor PERLONGHER, 2008). Para finalizar, gostaria de retomar aqui algumas linhas do "Manifesto Queer Nation" (2016), que pode ser lido tanto como uma referência às travestis queer que enfrentaram a polícia no confronto do Stone Wall Inn em 1969, nos Estados Unidos, como uma referência ao pensamento feminista que está na gênese dos textos das lésbicas pós-estruturalistas que deram corpo à teoria queer: "nossas irmãs mais fortes disseram aos nossos irmãos que havia duas coisas importantes para se lembrar sobre as revoluções que vêm. A primeira é que vamos apanhar. A segunda é que vamos vencer" (p. 4). Se em nosso trabalho, seja ele no ativismo das ruas, seja ele na prática intelectual e acadêmica, mantivermos um pouco que seja do espírito que move a citação acima, é porque definitivamente estamos traduzindo o queer: diariamente, reiteradamente e conscientemente.

\section{Agradecimentos}

Agradeço a Algemira Mendes de Macedo (professora da UESPI), Émerson da Cruz Inácio e Mário César Lugarinho (professores da USP), interlocutores cujas provocações deram origem a este ensaio. O presente trabalho é um dos resultados parciais do projeto de pesquisa "Contaminados, torturados, abjetos: por uma poética do corpo e da subjetividade na América Latina", por mim coordenado, que conta com auxílio financeiro do CNPq, na modalidade Bolsa de Produtividade em Pesquisa (Categoria PQ-2).

\section{Referências}

A QUEER MANIFESTO, 1990. Disponível em https://www.historyisaweapon.com/defcon 1/ queernation.html. Acesso em 20/08/2018.

ALÓS, Anselmo Peres. A letra, o corpo e o desejo: masculinidades subversivas no romance latinoamericano. Florianópolis: Mulheres, 2013.

ALÓS, Anselmo Peres. "Prolegomena queer: gênero e sexualidade nos estudos literários". Cadernos de Letras da UFF, n. 42, p. 199-21 7, 2011 . Disponível em http://www.cadernosdeletras.uff.br/joomla/ images/stories/edicoes/42/cotidiano3.pdf. Acesso em 20/09/2018.

ALTHUSSER, Louis. Ideologia e aparelhos ideológicos do Estado. Lisboa: Presença; Martins Fontes, 1974.

ALTHUSSER, Louis. Posições-1. Rio de Janeiro: Graal, 1978.

ANDRADE, Oswald de. "O manifesto antropófago". In: TELES, Gilberto Mendonça (Org.). Vanguarda européia e modernismo brasileiro: apresentação e crítica dos principais manifestos vanguardistas. 3. ed. Petrópolis: Vozes; Brasília: INL, 1976. p. 293-300.

ANZALDÚA, Gloria. Borderlands/La Frontera: The New Mestiza. San Francisco: Aunt Lute Books, 1987.

BERLIN, Brent; KAY, Paul. Basic Color Terms: their universality and evolution. Berkeley: The University of California Press, 1969.

BUTLER, Judith. Gender Trouble. London: Routledge, 1990.

BUTLER, Judith. Bodies that Matter. London: Routledge, 1993.

${ }^{13}$ Cf. http://daspu.com.br/. Acesso em 20/09/2018. Cf. também LENZ, Flávio. Daspu, a moda sem-vegonha. Rio de Janeiro: Aeroplano, 2008. 
BUTLER, Judith. The Psychic Life of Power. London: Routledge, 1997.

BUTLER, Judith. Problemas de gênero. Tradução de Renato Aguiar. Rio de Janeiro: Civilização Brasileira, 2003.

BUTLER, Judith. Undoing Gender. London: Routledge, 2004.

CAMPOS, Haroldo de. Metalinguagem e outras metas. 2. ed. 4. Reimpressão. São Paulo: Perspectiva, 2006.

CAMPOS, Augusto de; CAMPOS, Haroldo de. Traduzir e trovar. Campinas: Papirus, 1968.

CONNELL, Robert William. Masculinities. Berkeley: The University of California Press, 1995.

CONNOR, Steven. Teoria e valor cultural. São Paulo: Loyola, 1992.

CRIMP, Douglas (Ed.). AIDS: Cultural Analysis/Cultural Activism. Cambridge: MIT Press, 1988.

CRIMP, Douglas; ROLSTON, Adam. AIDS Demo Graphics. Seattle: Bay Press, 1990.

DE LAURETIS, Teresa (Ed.). "Queer Theory: Lesbian and Gay Sexualities". Differences: A Journal of Feminist Cultural Studies, v. 3, n. 2, Summer 1991. (Special Issue)

DERRIDA, Jacques. Gramatologia. São Paulo: Perspectiva, 1973.

FOUCAULT, Michel. História da Sexualidade I. Tradução de Maria Thereza da Costa Albuquerque e J. A. Guilhon Albuquerque. Rio de Janeiro: Graal, 1988.

FOUCAULT, Michel. Microfísica do poder. 8. ed. Rio de Janeiro: Graal, 1989.

FOUCAULT, Michel. História da sexualidade II. Rio de Janeiro: Graal, 1990.

FOUCAULT, Michel. Vigiar e punir: nascimento da prisão. 29. ed. Rio de Janeiro: Vozes, 1997.

FUSS, Diana (Ed.). Inside/Out: Lesbian Theories, Gay Theories. London: Routledge, 1991.

GENETTE, Gérard. Paratextos editoriais. São Paulo: Ateliê Editorial, 2009.

JAGOSE, Anamarie. Queer Theory: an introduction. New York: New York University Press, 1996.

KAY, Paul; KEMPTON, Willett. "What is the Sapir-Whorf hypothesis?". American Anthropologist, n. 86, p. 65-79, 1984.

LACAN, Jacques. Le seminaire, livre XXI: Les non-dupes errent (1973-1974). (Inédito). Transcrição em francês disponível na internet na página do psicanalista Patrick Valas. Disponível em http:// www.valas.fr/Jacques-Lacan-Les-non-dupes-errent-1973-1974,249. Acesso em 20/10/2018.

LACAN, Jacques. Conferência proferida na Faculdade Universitária de Saint-Louis, em Bruxelas, em 10/03/1960. Disponível em francês na página "Pas-tout Lacan". Disponível em http://www.ecolelacanienne.net/bibliotheque.php?id=10. Acesso em 20/10/2018.

LACAN, Jacques. Le séminaire, livre II: Le moi dans la théorie de Freud et dans la technique de la psychanalyse (1953-1954). Paris: Seuil, 1978.

LACAN, Jacques. O seminário, livro II: O eu na teoria de Freud e na técnica da psicanálise. Rio de Janeiro: Zahar, 1985.

LACAN, Jacques. Le seminaire, livre XXII: RSI (1974-1975). (Seminário inédito, transcrição em francês disponível na internet na página do psicanalista Patrick Valas). Disponível em http://www.valas.fr/ Jacques-Lacan-RSI-1974-1975,288. Acesso em 20/10/2018.

LACAN, Jacques. Le seminaire, livre XXIII: Le sinthome (1975-1976). Paris: Seuil, 2003.

LACAN, Jacques. O seminário, livro XXIII: O sinthoma. Rio de Janeiro: Zahar, 2007.

LOURO, Guacira Lopes. Um corpo estranho: ensaios de teoria queer. Belo Horizonte: Autêntica, 2004.

MANIFESTO QUEER NATION. Tradução de Roberto Romero. Cadernos de Leitura, Belo Horizonte, n. 53, novembro 2016. Disponível em https://chaodafeira.com/catalogo/caderno-n-53-manifesto-queernation/. Acesso em 13/08/2018. 
LUGARINHO, Mário César. "Como traduzir a teoria queer para a língua portuguesa". Gênero, Niterói, UFF, v. 2, n. 1, p. 36-46, 2001.

McGEE, Patrick. Telling the Other. Ithaca: Cornell University Press, 1992.

MISKOLCCI, Richard. O desejo de nação. São Paulo: Annablume, 2013.

PELÚCIO, Larissa. "Traduções e torções, ou o que se quer dizer quando dizemos queer no Brasil?". Periódicus, Salvador, v. 1, n. 1, p. 1-24, 2014.

PELÚCIO, Larissa. "Subalterno quem, cara pálida? Apontamentos às margens sobre póscolonialismos, feminismos e estudos queer". Contemporânea, São Carlos, v. 2, n. 2, p. 395-418, jul.-dez. 2012.

PERLONGHER, Nestor. O negócio do michê. 2. ed. São Paulo: Fundação Perseu Abramo, 2008.

PRADA, Monique. Putafeminista. São Paulo: Veneta, 2018. (Coleção Baderna)

PUAR, Jasbir. Terrorist Assemblages: Homonationalism in Queer Times. Durham: Duke University Press, 2007.

RIBEIRO, Djamila. O que é lugar de fala? Belo Horizonte: Letramento, 2016.

SCHULMAN, Sarah. Ties That Bind: Familial Homophobia and Its Consequences. New York: The New Press, 2009.

SCHULMAN, Sarah. Israel/Palestine and the Queer Internacional. Durham: Duke University Press, 2012.

TREVISAN, João Silvério. Devassos no Paraíso. 2. ed. revista e ampliada. Rio de Janeiro: Record, 2000.

Anselmo Peres Alós (anselmoperesalos@gmail.com) é líder do Grupo de Pesquisa "Feminismos, estudos de gênero e teoria queer" (UFSM/CNPq). Membro da ANPOLL, da ANPOF e da ABRALIC. Autor dos livros A letra, o corpo e o desejo: masculinidades subversivas no romance latino-americano (Florianópolis: Editora Mulheres, 2013) e Leituras a contrapelo da narrativa brasileira: redes intertextuais de gênero, raça e sexualidade (Santa Maria: PPG-L Editores, 2017).

COMO CITAR ESSE ARTIGO DE ACORDO COM AS NORMAS DA REVISTA

ALÓs, Anselmo Peres. "Traduzir o queer: uma opção viável?". Revista Estudos Feministas, Florianópolis, v. 28, n. 2, e60099, 2020.

CONTRIBUIÇÃO DE AUTORIA

Não se aplica.

FINANCIAMENTO

Bolsa de Produtividade em Pesquisa PQ-2 (CNPq).

CONSENTIMENTO DE USO DE IMAGEM

Não se aplica.

APROVAÇÃO DE COMITÊ DE ÉTICA EM PESQUISA

Não se aplica.

CONFLITO DE INTERESSES

Não se aplica.

LICENÇA DE USO

Este artigo está licenciado sob a Licença Creative Commons CC-BY International. Com essa licença você pode compartilhar, adaptar, criar para qualquer fim, desde que atribua a autoria da obra. 


\section{HISTÓRICO}

Recebido em 06/11/2018

Reapresentado em 19/10/2019

Aprovado em 10/02/2020 